\title{
The Small GTPase Rab7 Controls the Endosomal Trafficking and Neuritogenic Signaling of the Nerve Growth Factor Receptor TrkA
}

\author{
Smita Saxena, ${ }^{1}$ Cecilia Bucci, ${ }^{2}$ Joachim Weis, ${ }^{1,3}$ and Alex Kruttgen ${ }^{1,3}$ \\ ${ }^{1}$ Abteilung Neuropathologie, Institut für Pathologie, Universität Bern, CH-3010 Bern, Switzerland, ${ }^{2}$ Dipartimento di Scienze e Tecnologie Biologiche ed \\ Ambientali, Università di Lecce, 73100 Lecce, Italy, and ${ }^{3}$ Institut für Neuropathologie, Universitätsklinikum der Rheinisch-Westfälischen Technischen \\ Hochschule Aachen, D-52074 Aachen, Germany
}

\begin{abstract}
Nerve growth factor (NGF) and its TrkA receptor exert important bioactivities on neuronal cells such as promoting survival and neurite outgrowth. Activated TrkA receptors are not only localized on the cell surface but also in signaling endosomes, and internalized TrkA receptors are important for the mediation of neurite outgrowth. The regulation of the endosomal trafficking of TrkA is so far unknown. Because the endosome-associated GTPase Rab7 coimmunoprecipitated with TrkA, we examined whether the endosomal trafficking of TrkA might be under the control of Rab7. Inhibiting Rab7 by expression of a green fluorescent protein-tagged, dominant-negative Rab7 variant resulted in endosomal accumulation of TrkA and pronounced enhancement of TrkA signaling in response to limited stimulations with NGF, such as increased activation of Erk1/2 (extracellular signal-regulated kinase 1/2), neurite outgrowth, and expression of GAP-43 (growth-associated protein 43). Our studies show that the endosomal GTPase Rab7 controls the endosomal trafficking and neurite outgrowth signaling of TrkA. Because mutations of Rab7 are found in patients suffering from hereditary polyneuropathies, dysfunction of Rab7 might contribute to neurodegenerative conditions by affecting the trafficking of neurotrophins. Moreover, strategies aimed at controlling Rab7 activity might be useful for the treatment of neurodegenerative diseases.
\end{abstract}

Key words: polyneuropathy; neurodegeneration; neurotrophin; neurite outgrowth; Charcot-Marie-Tooth; retrograde transport

\section{Introduction}

Because of their complex morphology, neurons have to integrate a multitude of receptor-mediated signals conveyed from spatially remote locations. Nerve growth factor (NGF) is the prototypical neuronal growth factor that promotes neuronal survival and neurite outgrowth (Snider, 1994). NGF mediates its effects by binding and activating its receptor-tyrosine kinase (RTK) TrkA (Kaplan et al., 1991; Klein et al., 1991). Target-derived NGF activates its TrkA receptors on axon tips (Ehlers et al., 1995). Thus, the NGF-triggered signal needs to be transmitted retrogradely over long distances from the synapse to the cell body to elicit transcriptional responses (Neet and Campenot, 2001; von Bartheld, 2004). Recent work demonstrated that signaling endosomes containing NGF and activated TrkA are transported ret-

\footnotetext{
Received May 20, 2005; revised 0ct. 10, 2005; accepted 0ct. 15, 2005.

This work was supported by grants from the Swiss National Science Foundation, the START Program of the Rheinisch-Westfälische Technische Hochschule (RWTH) Aachen, the Ministero dell'Istruzione dell'Università e della Ricerca Scientifica (MIUR PRIN04), and Telethon-Italy (GGP05160 to C.B.). We thank J. C. Sarria (Faculte des Sciences de la Vie, École Polytechnique Fédérale de Lausanne, Lausanne, Switzerland) for help with confocal imaging, J. Senderek (Universitätsklinikum der RWTH Aachen) for help with sequencing, S. Rossaint for help with graphic art, and Genentech (South San Francisco, CA) for providing recombinant NGF.

Correspondence should be addressed to Dr. A. Kruttgen, Institute of Neuropathology, University Hospital, RWTH Aachen, Pauwelsstrasse 30, 52074 Aachen, Germany. E-mail: akruettgen@ukaachen.de.

S. Saxena's present address: Friedrich Miescher Institut, Maulbeerstrasse 66, CH-4058 Basel, Switzerland.

DOI:10.1523/JNEUROSCI.2029-05.2005

Copyright $\odot 2005$ Society for Neuroscience $\quad$ 0270-6474/05/2510930-11\$15.00/0
}

rogradely from the axon to the cell body (Ginty and Segal, 2002; Howe and Mobley, 2004).

GTPases are a large group of important proteins. Whereas the members of the Ras subfamily (such as H-Ras and Rap1) are directly involved in signal transduction by activating mitogenactivated protein kinases (MAPKs) (Wu et al., 2001), the Rab (Ras-related in brain) subfamily is classically known for its direct involvement in organelle trafficking. The different Rab GTPases localize to the cytosolic face of specific intracellular membranes, at which they regulate distinct steps in membrane traffic pathways (Stenmark and Olkkonen, 2001). Most recently, however, it is emerging that Rabs are also linked to signal transduction by regulating the trafficking of signaling receptors (Miaczynska et al., 2004). One member of this family, Rab7, plays a well established role in controlling the trafficking of early endosomes and late endosomes (Bucci et al., 2000; Somsel Rodman and Wandinger-Ness, 2000).

It was revealed recently that activated TrkA is present in clathrin-coated vesicles, early endosomes, and late endosomes, which are also known as multivesicular bodies (Howe et al., 2001; Delcroix et al., 2003; Saxena et al., 2005). These organelles are considered to be mobile signaling platforms for NGF. But how is the movement of these signaling organelles regulated? So far, little is known about this important question. Because dynein mediates the vesicular minus-end transport of TrkA along microtubules (Yano et al., 2001; Heerssen et al., 2004) and Rab7 con- 
trols dynein function (Jordens et al., 2001), we investigated whether Rab7 plays a role in the endosomal transport of TrkA. We found that Rab7 interacts with TrkA and that inhibition of Rab7 activity was associated with endosomal accumulation of TrkA and augmented TrkA signaling in NGF-stimulated PC12 cells, leading to impressively enhanced neurite outgrowth in response to limited stimulations with NGF. The significance of our results is twofold. First, our findings suggest a novel mechanistic link between the endosomal trafficking and signaling of neuronal RTKs, because both processes are under control of Rab7. Second, our results suggest a pathological mechanism for certain forms of Charcot-Marie-Tooth neuropathy type 2B (CMT2B) and hereditary sensory neuropathy type 1 (HSN1), because mutations within the Rab7 gene are associated with these so far incurable neurodegenerative diseases (Verhoeven et al., 2003; Houlden et al., 2004).

\section{Materials and Methods}

Reagents. Recombinant purified NGF was a gift from Genentech (South San Francisco, CA). All other chemicals were from Sigma (St. Louis, $\mathrm{MO}$ ), and cell culture media were from Invitrogen (San Diego, CA). The following antibodies were used: rabbit anti-Rab7 (Santa Cruz Biotechnology, Santa Cruz, CA); mouse anti-phospho extracellular signalregulated kinase (Erk), mouse anti-Erk1/2, rabbit anti-Akt, mouse antiphospho Akt, and rabbit anti-phosphoTrkA (all from Cell Signaling Technologies, Beverly, MA); rabbit anti-TrkA (Upstate Biotechnology, Lake Placid, NY); mouse anti-TrkA (Zymed, San Francisco, CA); and AlexaFluor-labeled secondary antibodies and DiI-labeled low-density lipoprotein (LDL) (all from Invitrogen, Eugene, OR). The construction of wild-type (WT)-Rab7/green fluorescent protein (GFP), dominantnegative (DN)-Rab7/GFP (Rab7 T22N), and constitutive active (CA)Rab7/GFP (Rab7 Q67L) subcloned into the pEGFP-C1 vector, has been described (Bucci et al., 2000).

Cell culture and transient transfections. Rat dorsal root ganglion (DRG) neurons were prepared as described previously (Thier et al., 1995). PC12 cells were cultured as described previously (Saxena et al., 2004). Transfections using Lipofectamine 2000 (Invitrogen) were performed according to the manufacturer's instructions. We routinely observed transfection efficiencies of $\sim 20 \%$ in PC12 cells.

NGF stimulation protocol. For all NGF stimulations, a concentration of $200 \mathrm{ng} / \mathrm{ml}$ of recombinant human NGF was applied. Eighteen hours after transfection, PC12 cells were washed and stimulated with NGF for 10 min in serum-free medium (DMEM and 0.1\% BSA) to drive internalization of TrkA into endosomes. Subsequently, PC12 cells loaded with internalized activated TrkA bound to NGF (Grimes et al., 1996) were chilled on ice to arrest endosomal trafficking, and the remaining surfacebound NGF was removed by three washes with ice-cold "surface strip buffer" (0.2 M acetic acid and $0.5 \mathrm{M} \mathrm{NaCl}$ ) (Bernd and Greene, 1984), followed by three washes with ice-cold PBS. Afterward, cells were reincubated for the indicated time points in prewarmed serum-free medium and subsequently processed for immunofluorescence or biochemical assays.

Confocal immunofluorescence microscopy. After stimulations, cells were chilled on ice, fixed with $4 \%$ paraformaldehyde (PFA) for $10 \mathrm{~min}$, and permeabilized with $0.1 \%$ Triton X-100 for $30 \mathrm{~min}$ at room temperature, as described recently (Saxena et al., 2004). Primary antibodies were incubated overnight at $4^{\circ} \mathrm{C}$, followed by washes and a $1 \mathrm{~h}$ incubation with appropriate secondary antibodies at room temperature. Cells were viewed either with a Leica (Nussloch, Germany) TCSNT confocal microscope for triple immunolabelings or with a Zeiss (Oberkochen, Germany) LSM 410 confocal microscope for double immunolabelings. Optical sections were $100 \mathrm{~nm}$. We compared the size of TrkA endosomes in NGF-stimulated PC12 cells transfected with DN-Rab7/GFP and neighboring untransfected cells by using LCSlite software (Leica). Ten single endosomes per cell were selected randomly and marked as a region of interest, keeping a constant $Z=2.5-3.0 \mu \mathrm{m}$ for every image. The calculated area was plotted as the size of individual TrkA-bearing endosomes.
Ten transfected versus untransfected cells (10 endosomes per cells) from three different experiments were quantified.

Neurite outgrowth assay. For assaying neurite outgrowth, PC12 cells were transfected with GFP (pEGFP-N1; Clontech, Palo Alto, CA), WTRab7/GFP, CA-Rab7/GFP, and DN-Rab7/GFP plasmids. Eighteen hours after transfection, cells were stimulated for $10 \mathrm{~min}$ with $200 \mathrm{ng} / \mathrm{ml} \mathrm{NGF}$. Subsequently, NGF was stripped from the cell surface as described above. Then cells were reincubated in serum-free medium for $24 \mathrm{~h}$ and fixed with 4\% PFA. Epifluorescent images were taken using Act-1 software (Nikon, Melville, NY). Neurite length was measured from at least 150 cells per condition, derived from nine randomly selected fields per coverslip.

Surface biotinylation-based assays. Depletion of TrkA surface levels in response to NGF or internalization of TrkA after NGF treatment was determined by using nonmembrane-permeable, biotin-tagged crosslinking reagents (Pierce, Rockford, IL), performed as described previously (Saxena et al., 2005).

Immunoprecipitations. Sixteen hours after transfections, PC12 cells were washed, switched to DMEM/BSA, and stimulated with NGF for 10 min, followed by surface strip and reincubation in serum-free medium for the indicated time points. Cells were lysed for $15 \mathrm{~min}$ on ice in lysis buffer, which consisted of 0.5\% NP-40, 25 mM Tris, pH 7.5, $100 \mathrm{~mm}$ $\mathrm{NaCl}$, and $50 \mathrm{~mm} \mathrm{NaF}$ supplemented with a protease inhibitor mixture (Roche Diagnostics, Basel, Switzerland) and a phosphatase inhibitor mixture (Sigma). Lysates were precleared by centrifugation, and $500 \mu \mathrm{g}$ of each lysate was subjected to immunoprecipitation by rotation overnight at $4^{\circ} \mathrm{C}$ with $3 \mu \mathrm{g}$ of anti-Rab7 (Santa Cruz Biotechnology) or $1.5 \mu \mathrm{g}$ of anti-GFP (Roche Diagnostics), followed by incubation with protein A-Sepharose (Amersham Biosciences, Uppsala, Sweden). Immunoprecipitates were washed three times in $0.1 \% \mathrm{NP}-40,25 \mathrm{~mm}$ Tris- $\mathrm{HCl}, \mathrm{pH}$ 7.5 , and $150 \mathrm{~mm} \mathrm{NaCl}$ supplemented with a phosphatase inhibitor mixture. A last wash with ice-cold $10 \mathrm{~mm}$ Tris- $\mathrm{HCl}, \mathrm{pH} 7.5$, was done before precipitates were boiled in Laemmli buffer and subjected to SDS-PAGE.

Biochemical assay for lysosomal degradation. Equal numbers of PC12 cells were transfected with GFP or DN-Rab7/GFP. Eighteen hours after transfection, cells were treated for $30 \mathrm{~min}$ in the absence or presence of the protein synthesis blocker cycloheximide (CHX; $10 \mu \mathrm{g} / \mathrm{ml})$. Subsequently, cells were stimulated by the addition of NGF $(200 \mathrm{ng} / \mathrm{ml})$ or left unstimulated for $10 \mathrm{~min}$, surface NGF was removed as described above, and cells were reincubated for 6 or $12 \mathrm{~h}$ in the presence of CHX in serum-free medium. Protein lysates were prepared and subjected to SDSPAGE and Western blotting using antibodies against TrkA.

Statistical analyses. All presented experiments were performed at least three times with similar results. Statistical data are shown as mean \pm SD. Differences were analyzed using the unpaired Student's $t$ test with unequal variances.

\section{Results}

\section{Rab7 is expressed in neurons and PC12 cells}

Previous studies have detected Rab7 protein by immunofluorescence in primary hippocampal neurons (Parton et al., 1992) and by Western blotting in the neuronal cell line PC12 (Samuels et al., 2001). Using Western blotting of protein lysates derived from rat PC12 cells and embryonic rat cerebral cortex and cerebellum, we confirmed the presence of endogenous Rab7 protein in these neuronal cells (Fig. $1 A$ ). We also examined the intracellular distribution of Rab7 by immunofluorescence and confocal microscopy (Fig. $1 B$ ). These experiments revealed that $\mathrm{Rab} 7$ was present within the cell body of undifferentiated PC12 cells and primary rat embryonic DRG sensory neurons. Importantly, a vesicular staining pattern indicative of association with endosomes was also observed within neuronal processes of primary rat embryonic sensory neurons. These data suggest that TrkA might play a regulatory role in neuronal endosomal trafficking. 
A

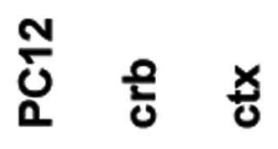

\section{straight lysate IB: anti-Rab7}

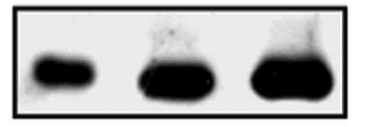

Rab7
B

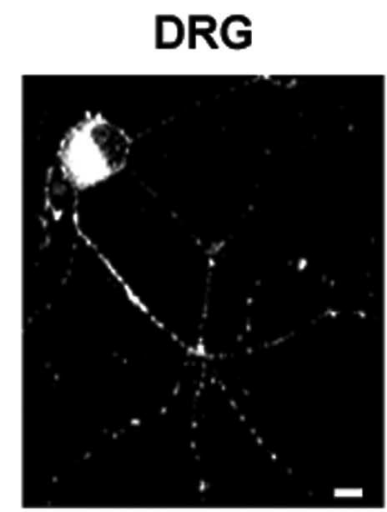

Rab7

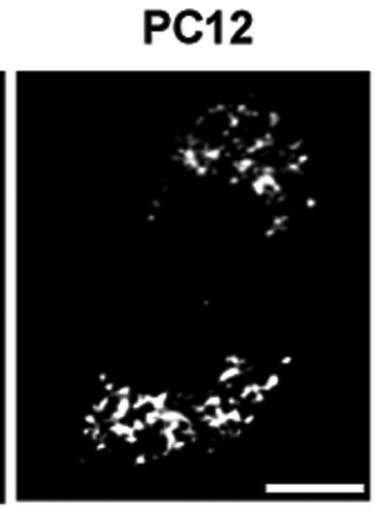

Rab7
Figure 1. Expression of Rab7 protein in PC12 cells and neurons. $\boldsymbol{A}$, Western blot analysis of equal amounts of protein lysates from embryonic rat cerebellum (crb) and cortex (ctx), as well as from undifferentiated PC12 cells. A $23 \mathrm{kDa}$ band corresponding to Rab7 was observed in all lanes. A representative blot is shown. IB, Immunoblot. $\boldsymbol{B}$, Confocal immunofluorescence analysis of Rab7 in fixed and permeabilized DRGs and PC12 cells. Vesicular staining for Rab7 in PC12 cells and within neuronal processes and cell bodies of DRG neurons. A representative experiment is shown. Scale bars, $10 \mu \mathrm{m}$.

\section{Inhibition of Rab7 blocks the endosomal trafficking of TrkA} Rab7 controls endosomal trafficking via its GTPase activity. Active GTP-bound Rab7 increases the velocity of dynein-mediated endosomal transport along microtubules (Bananis et al., 2004). A DN form of Rab7 was established (Rab7T22N) and used frequently during the last decade to examine the potential involvement of Rab7 in a diverse set of biological mechanisms (Feng et al., 1995; Mukhopadhyay et al., 1997; Cantalupo et al., 2001; Rupper et al., 2001; Sieczkarski and Whittaker, 2003). So far, no nonspecific effect of this construct on other Rab family members has been reported in non-neuronal cell lines. We confirmed the specificity of DN-Rab7/GFP for neuronal cell lines by demonstrating that expression of DN-Rab7/GFP neither affected the secretory pathway nor the recycling pathway in PC12 cells (supplemental Fig. 1, available at www.jneurosci.org as supplemental material). Interestingly, DN-Rab7/GFP showed a membraneassociated distribution in transfected PC12 cells, whereas in transfected non-neuronal cells, a diffuse cytoplasmic distribution has commonly been observed (Bucci et al., 2000). The reason for this difference is currently unclear. Potentially, different permeabilization/fixation protocols or instrinsic cell-type-dependent differences might influence the subcellular distribution of DN-Rab7/GFP.

One important finding that emerged from previous studies in non-neuronal cell lines was that expression of DN-Rab7 does not influence the recycling pathway but effectively blocks the early and late endosomal trafficking of LDL (Vitelli et al., 1997). The effect of DN-Rab7 on RTK trafficking and their signaling in nonneuronal cells or neuronal cells has not been assessed yet. Therefore, we first examined whether inhibition of Rab7 activity leads to endosomal accumulation of TrkA. PC12 cells were transiently transfected with DN-Rab7/GFP, and 18 h later, cells were incubated for $1 \mathrm{~h}$ with fluorescent-labeled LDL $(30 \mu \mathrm{g} / \mathrm{ml})$ to allow cells to internalize this classical endocytosis marker that is sorted from clathrin-coated vesicles via early endosomes to late endosomes. PC12 cells were then washed, and NGF was added for 10 min. This short stimulation protocol allowed the binding of NGF to TrkA, resulting in TrkA activation and internalization of most surface TrkA into endosomes (Jullien et al., 2002; Saxena et al., 2005). Afterward, surface-bound NGF and LDL were removed by washing with a high-salt/low-pH buffer. This treatment protocol effectively removes bound ligands from their surface receptors (Bernd and Greene, 1984). Subsequently, PC12 cells were chased in serum-free medium for $2 \mathrm{~h}$, and the cells were chilled on ice, washed, fixed, and immunostained for TrkA. As shown in Figure 2 , there were larger vesicles containing both TrkA (blue) and endosomal LDL (red) in DN-Rab7-transfected cells (green) compared with untransfected neighboring cells.

We next quantified the size of TrkA endosomes (defined by colocalization of TrkA with LDL) after NGF stimulation in DNRab7/GFP-expressing cells as well as in neighboring untransfected cells (data not shown). The average size of TrkAcontaining endosomes in DN-Rab7/GFP-expressing cells was $\sim 607,000 \mathrm{~nm}^{2}\left( \pm 224,607 \mathrm{~nm}^{2}\right)$, whereas in untransfected neighboring cells, TrkA endosomal size was $170,123 \mathrm{~nm}^{2}$ $\left( \pm 80,609 \mathrm{~nm}^{2}\right)$. Thus, inhibition of Rab7 activity resulted in accumulation of TrkA in enlarged endosomes that were, on average, 3.7-fold larger than in neighboring untransfected cells $(p<$ $0.001)$.

Biochemical experiments were performed to test whether the results from the immunofluorescence experiments showing that Rab7 is important for the endosomal transport of TrkA could be confirmed with a different experimental design. Using surface biotinylation assays with a nonpermeable cross-linker (Saxena et al., 2004), we examined whether the expression of DN Rab7 influenced the initial internalization of TrkA (Fig. 3A). As shown previously (Saxena et al., 2005), NGF stimulation for $30 \mathrm{~min}$ led to almost complete surface downregulation of TrkA in control PC12 cells (Fig. $3 A$, compare lanes 1,2 ). The same surface downregulation was found in DN-Rab7/GFP-expressing cells (Fig. 3A, compare lanes 3,4$)$, suggesting that Rab7 does not affect the initial NGF-driven internalization of TrkA. This finding also excludes the possibility of increased TrkA recycling in DN-Rab7/ GFP-transfected cells, because this should lead to higher surface levels after ligand addition in DN-Rab7/GFP cells. Our result is in accordance with the literature that shows that Rab7 does not influence trafficking upstream of early endosomes and that Rab7 does not affect trafficking within the recycling pathway (Vitelli et al., 1997). Together with the data presented in supplemental Fig. 1 (available at www.jneurosci.org as supplemental material), this demonstrates that DN-Rab7/GFP exerts no apparent unspecific effects on initial endocytic events, nor on the secretory pathway or on the recycling pathway.

Does expression of DN-Rab7/GFP prolong the persistence of internalized TrkA? To answer this question, we used a surfacebiotinylation internalization assay with a nonpermeable but cleavable cross-linker (Saxena et al., 2004). As shown in Figure 

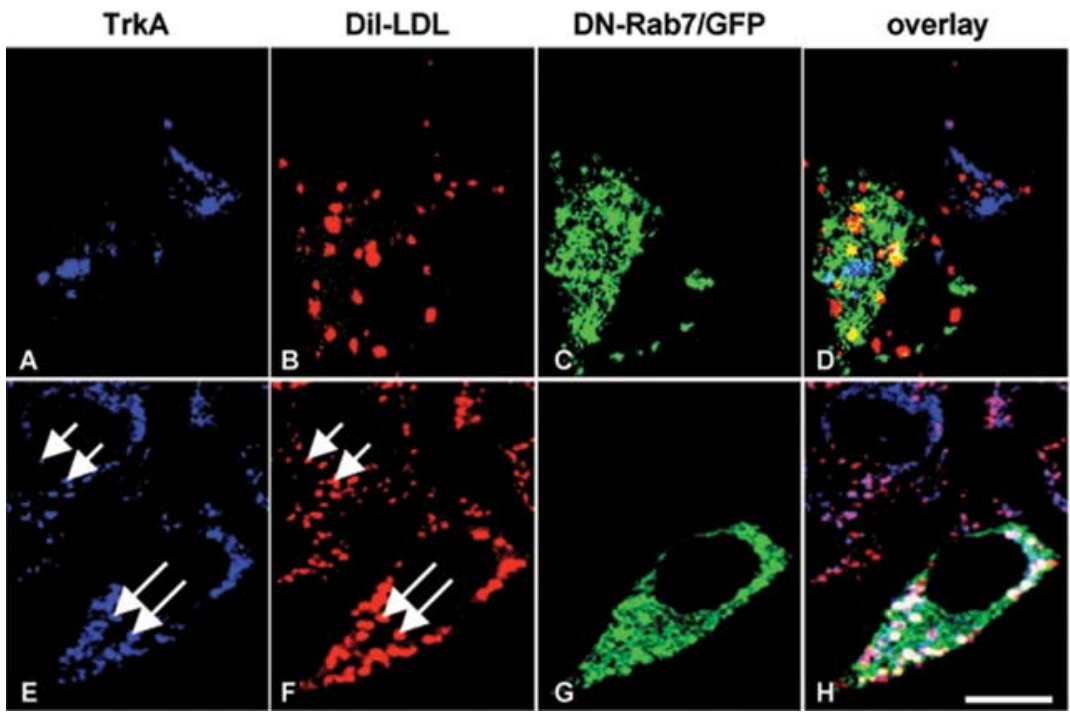

Figure 2. Rab7 inhibition by transient expression of DN-Rab7/GFP results in endosomal accumulation of TrkA. DN-Rab7/GFPtransfected PC12 cells were stimulated without NGF $(-\mathrm{NGF} ; \boldsymbol{A}-\boldsymbol{D})$ or with NGF $(+\mathrm{NGF} ; \boldsymbol{E}-\boldsymbol{H})$ in the presence of fluorescently labeled LDL (Dil-LDL) to allow for endocytosis of LDL and TrkA, followed by surface strip and reincubation in ligand-free DMEM/ BSA for $2 \mathrm{~h}$. Subsequently, cells were fixed, permeabilized, and stained for TrkA. The arrows indicate vesicles containing TrkA and LDL. Colocalization of LDL (red) and TrkA (blue) in enlarged vesicles in DN-Rab7/GFP-expressing cells (green) is shown. A representative experiment is shown. Scale bar, $8 \mu \mathrm{m}$.

$3 B$, a brief stimulation with NGF for 10 min was sufficient to induce robust internalization of surface TrkA receptors in both DN-Rab7/GFP- and GFP-expressing control cells (compare lanes 1, 2). However, endocytosed TrkA receptors were more persistent in DN-Rab7/GFP-expressing cells than in GFPexpressing control cells (Fig. 3B, lanes 3-5).

In PC12 cells, endocytosed TrkA is sorted from early endosomes to late endosomes and eventually degraded within lysosomes (Saxena et al., 2005). To further investigate whether expression of DN-Rab7/GFP inhibits the lysosomal degradation of TrkA, we pretreated equal numbers of DN-Rab7/GFP- or GFPtransfected control PC12 cells with CHX for 30 min to inhibit de novo protein synthesis (Longva et al., 2002). Subsequently, cells were stimulated for $10 \mathrm{~min}$ with NGF to drive internalization of surface TrkA receptors. Cells were cooled on ice and washed with ice-cold PBS, and surface-bound ligand was removed by the addition of surface strip buffer. Then, PC12 cells loaded with internalized activated TrkA receptors were washed in PBS and rewarmed for different times in serum-free medium to allow endosomal TrkA traffic to proceed. Subsequently, cells were cooled and lysed, and protein lysates were subjected to immunoblotting for TrkA. As shown in Figure $3 C$ (lanes 5, 6), internalized TrkA was more persistent in DN-Rab7/GFP-expressing cells than in control cells (lanes 2, 3).

\section{Endogenous TrkA and Rab7 form a complex}

Previous work showed that Rab7 forms a complex with the molecular motors dynein and dynactin (Jordens et al., 2001). It is also known that Trk receptors directly interact with the dynein light chain (Yano et al., 2001). Therefore, the same amounts of PC12 cell lysates treated with or without NGF were immunoprecipitated with anti-Rab7 antibodies to test whether TrkA would be found in a direct or indirect complex with Rab7. As shown in Figure 4A, TrkA coimmunoprecipitated with Rab7 in an NGFdependent and time-dependent manner. Thus, besides dynein, Rab7 represents a novel traffic-related protein forming a complex with TrkA.
-NGF

Next, we wanted to confirm the specificity of the Rab7 antibodies used for the immunoprecipitation of endogenous Rab7. Unfortunately, no blocking peptide or preimmune serum was available commercially. However, given the availability of a well established GFP-tagged WT-Rab7 construct, we transfected WTRab7/GFP into PC12 cells and performed a NGF stimulation, followed by lysis. WT-Rab7/GFP was then precipitated with anti-tag antibody and blotted, and the nitrocellulose membranes were probed with anti-TrkA antibodies. As shown in Figure $4 B$, a time-dependent coimmunoprecipitation of TrkA and WT-Rab7/GFP was observed, confirming the results presented above in Figure $4 A$. Next, the subcellular localization of WT-Rab7/GFP in relation to TrkA was examined in transfected PC12 cells. As shown in Figure $4 C$, the transfected WTRab7/GFP construct (green) showed a vesicular subcellular localization, reminiscent of endogenous Rab7 staining shown in Figure 1. After stimulation with NGF for $30 \mathrm{~min}$, we observed an increased colocalization of WT-Rab7/GFP (green) with TrkA (red), as visualized by yellow fluorescence (Fig. 4C). These imaging results support the notion that Rab7 and TrkA both reside on shared vesicles.

\section{Inhibition of Rab7 potentiates the signaling of TrkA in response to brief stimulations with NGF}

In previous experiments, we established that Rab7 controls the endosomal trafficking of the RTK TrkA (Fig. 2). It has not yet been assessed whether Rab7 activity controls RTK signaling in general and TrkA signaling in particular. To visualize differences regarding NGF signaling in DN-Rab7/GFP-expressing PC12 cells with control cells, we performed the NGF stimulation protocol described above (compare Figs. 2, 3B): PC12 cells transfected with either DN-Rab7/GFP or control cells transfected with GFP were treated briefly for 10 min with NGF. Subsequently, surfacebound NGF was stripped (Bernd and Greene, 1984), and cells were reincubated in NGF-free medium for various time points. Such limited NGF stimulations were necessary to emphasize potential differences between control cells and cells with inhibited Rab7. Because most surface-exposed TrkA receptors are internalized after NGF addition within 10 min (Jullien et al., 2002) and because internalized TrkA receptors in PC12 cells do not join the recycling pathway (Hosang and Shooter, 1987; Bronfman et al., 2003; Saxena et al., 2005), our stimulation protocol involving surface stripping should load cells with activated TrkA receptors and minimize the contribution of surface-exposed activated TrkA receptors in subsequent signaling assays. Surface stripping was followed by lysis and immunoblotting of equal amounts of lysates. Interestingly, we observed higher and more sustained pTrkA levels in DN-Rab7/GFP cells compared with GFPexpressing control cells at 2, 6, and $24 \mathrm{~h}$ after a $10 \mathrm{~min}$ stimulation with NGF, followed by surface strip and reincubation in DMEM/ BSA (Fig. 5A). It should be noted that the DN-Rab7 effect is even more remarkable given that our transfection efficiency was $20 \%$, as assessed by GFP fluorescence on GFP-transfected control plates as well as on plates transfected with DN-Rab7/GFP. Den- 
A

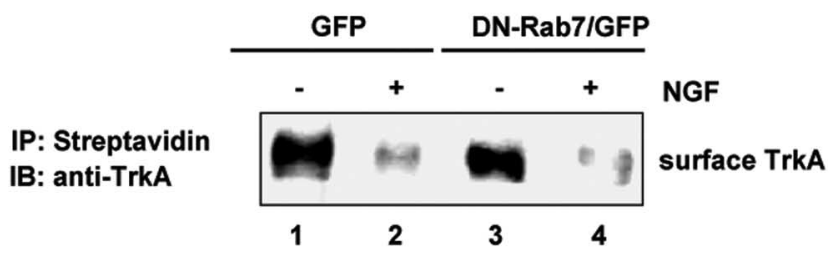

B

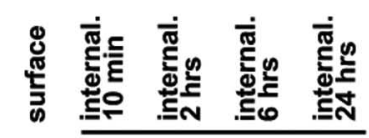

IP: Streptavidin

IB: anti-TrkA

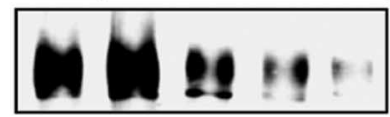

DN-Rab7/GFP

\section{IP: Streptavidin \\ IB: anti-TrkA}

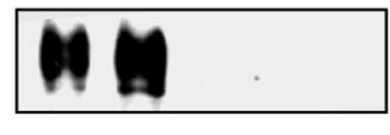

GFP

C

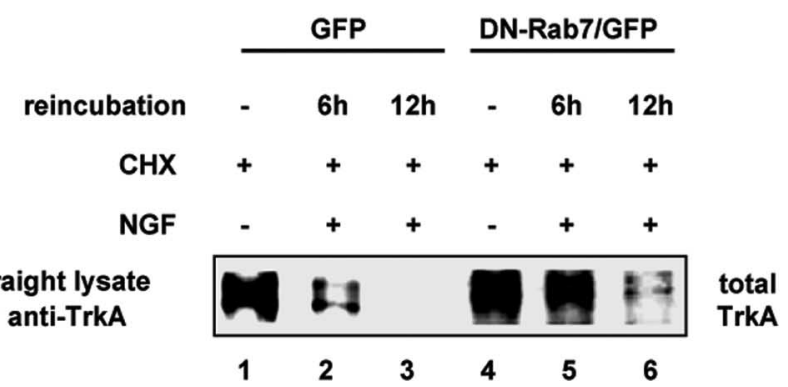

Figure 3. Intracellular persistence of internalized TrkA depends on Rab7 activity. $A$, Surface biotinylation of PC12 cells transfected with DN-Rab7/GFP or GFP (control). Cells were stimulated with NGF for $30 \mathrm{~min}$, chilled on ice and washed, and surface receptors were biotinylated. Then, cells were lysed, and lysates were subjected to precipitation with streptavidin beads, followed by immunoblot with an antibody against TrkA. Surface TrkA was internalized to a similar extent in both control cells expressing GFP (lanes 1, 2) and cells transfected with DN-Rab7/GFP (lanes 3 , 4). A representative blot is shown. $\boldsymbol{B}$, Surface biotinylation-based internalization assay of PC12 cells transfected with DN-Rab7/GFP or GFP (control). Surface proteins of PC12 cells were first biotinylated on ice with a cleavable membrane-impermeable cross-linker. Cells were then washed and incubated with NGF at $37^{\circ} \mathrm{C}$ for $10 \mathrm{~min}$. This step drives the internalization of biotinylated surface receptors. Afterward, cells were cooled on ice and washed, and the biotin of remaining surface-exposed biotinylated receptors was cleaved. This step leaves only internalized biotinylated receptors. Then, cells were rewarmed in NGF-free medium for different time points, as indicated. Afterward, cells were lysed, lysates were subjected to precipitation with streptavidin beads, and precipitates were immunoblotted with anti-TrkA. Both GFP and DNRab7/GFP samples were run on the same gel and probed on the same nitrocellulose membrane. Lane 1 (surface) reflects surface levels of TrkA before stimulation with NGF, whereas lanes 2-5 reflect the intracellular levels of internalized TrkA after different incubation periods in NGF-free medium. Prolonged intracellular persistence of TrkA in DN-Rab7/GFP-expressing cells (top, lanes 3-5) after 2 and $6 \mathrm{~h}$ of reincubation in NGF-free medium compared with GFP transfected control cells (bottom, lanes 3-5) is shown. A representative blot is shown. C, Same numbers of PC12 cells transiently transfected with either GFP (control) or DN-Rab7/GFP were pretreated for 30 min with the translation blocker CHX, followed by a 10 min NGF stimulation, and subsequently surface stripped for ligand removal. Cells were reincubated in serum-free medium in the presence of CHX. Then, cells were lysed, and lysates were immunoblotted for TrkA. The intracellular persistence of internalized TrkA is prolonged in DN-Rab7/GFP-expressing cells (lanes 5, 6) compared with GFP-expressing cells (lanes 2, 3). A representative blot is shown. IP, Immunoprecipitate; IB, immunoblot.
A

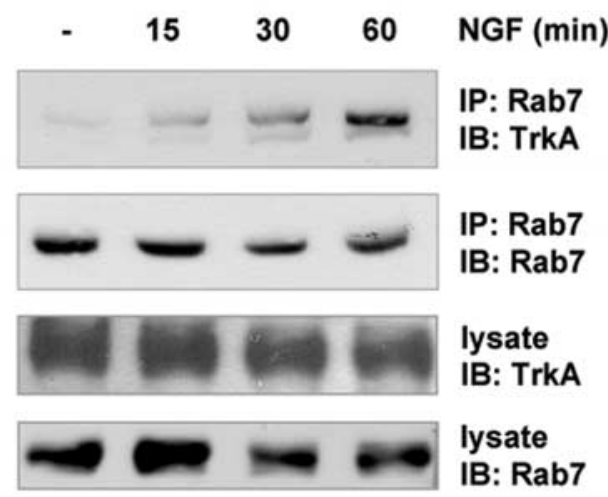

B

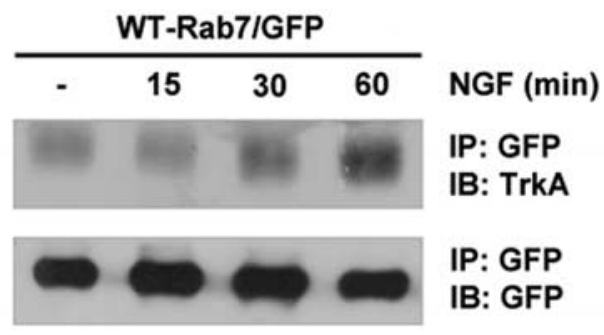

C

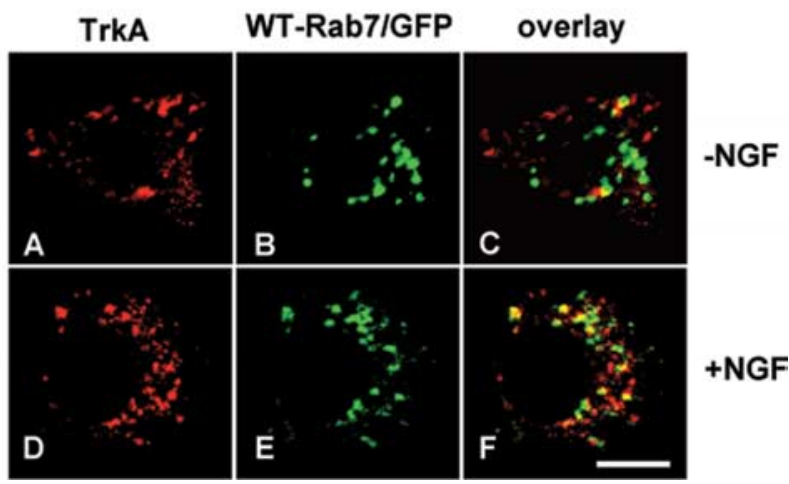

Figure 4. Association of TrkA with Rab7.A, PC12 cells were stimulated with NGF for different time points, and equal amounts of lysates were immunoprecipitated with antibodies against Rab7, followed by immunoblotting with antibodies directed against TrkA. Subsequently, the membrane was stripped and reprobed with antibodies against Rab7 to confirm that similar amounts of Rab7 were pulled down in each lane. To confirm that our lysates contain similar amounts of Rab7 or TrkA, equal amounts of lysates were immunoblotted with antibodies against TrkA or Rab7. Blots from a representative experiment are shown. $\boldsymbol{B}, \mathrm{PC} 12$ cells were transfected with WT-Rab7/GFP and stimulated with NGF for different time points. Equal amounts of lysates were immunoprecipitated with antibodies against the GFP tag to pull down Rab7/GFP, followed by immunoblotting with antibodies directed against TrkA. Subsequently, the membrane was stripped and reprobed with antibodies against GFP to confirm that similar amounts of Rab7/GFP were pulled down in each lane. Blots from a representative experiment are shown. C, PC12 cells were transfected with WT-Rab7/GFP and stimulated with or without NGF for 30 min. Cells were fixed, permeabilized, and stained for TrkA (red). Increased colocalization of WT-Rab7/GFP (green) with TrkA (red) appears as yellow in C and $\boldsymbol{F}$. Scale bar, $10 \mu \mathrm{m}$. $\mathbb{I P}$, Immunoprecipitate; IB, immunoblot.

sitometric quantification of four separate experiments was performed. As shown in Figure 5B, pTrkA levels in DN-Rab7/GFPexpressing cells were increased 5.4-fold at $2 \mathrm{~h}(p<0.01), 5.5$-fold at $6 \mathrm{~h}(p<0.01)$, and 7.8 -fold at $24 \mathrm{~h}(p<0.001)$ compared with pTrkA levels in GFP-expressing control cells at these time points. 


\section{A reincubation - $2 \mathrm{~h} \quad 6 \mathrm{~h} 24 \mathrm{~h}$

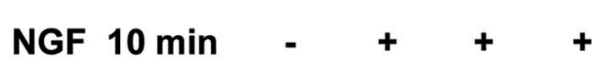

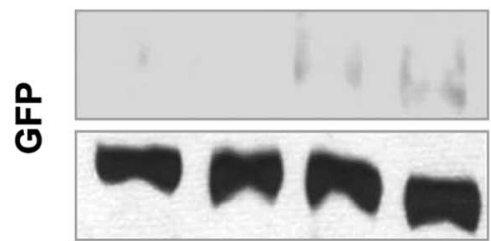

pTrkA

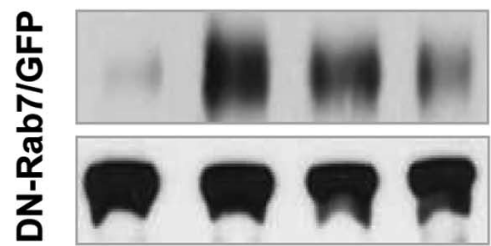

pTrkA

TrkA

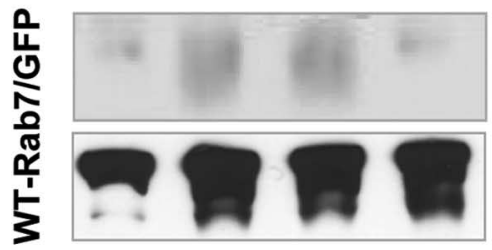

pTrkA

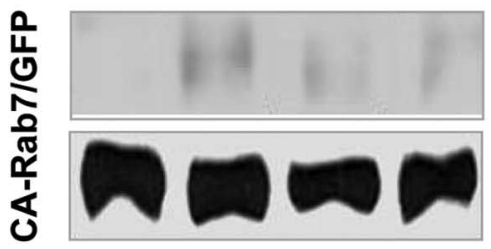

pTrkA

TrkA

B

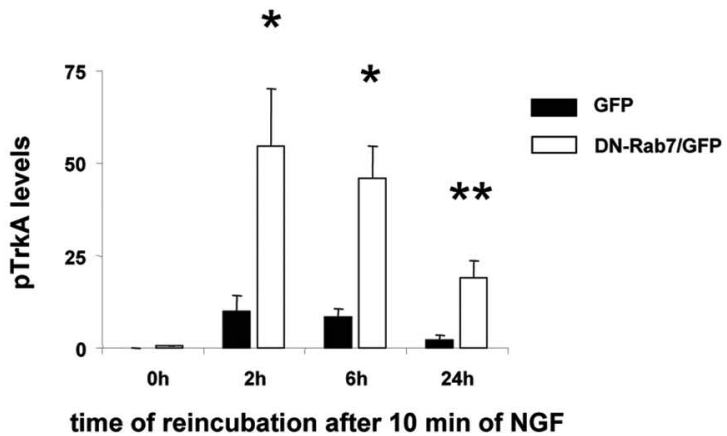

Figure 5. Enhanced TrkA phosphorylation in PC12 cells expressing DN-Rab7/GFP. A, PC12 cells transfected with GFP, DN-Rab7/GFP, WT-Rab7/GFP, or CA-Rab7/GFP were stimulated for 10 min with NGF, followed by ligand strip and reincubation in NGF-free medium for the indicated time points. Subsequently, cells were lysed, and equal amounts of protein were subjected to immunoblotting with antibodies directed against tyrosine-phosphorylated TrkA (pTrkA). Higher levels of $p$ TrkA were found even after $24 \mathrm{~h}$ of reincubation in serum-free medium compared with GFP-expressing cells. Subsequently, membranes were stripped and reprobed with antibodies against unphosphorylated TrkA as loading control (bottom). Representative blots are shown. $\boldsymbol{B}$, Films derived from four separate experiments were quantified by densitometry. Values of $\mathrm{p} T r k A$ are compared with control values (unstimulated). Error bars represent SD. ${ }^{*} p<$ $0.05 ;{ }^{* *} p<0.01$.

Previous work has also assessed the influence of a wild-type Rab7/GFP construct (WT-Rab7/GFP) and a constitutive active construct (CA-Rab7/GFP, with residue Q67 mutated to L) on endosomal traffic. In non-neuronal cells, overexpression of CARab7/GFP slightly enhanced the degradation of LDL while in- creasing the size of lysosomes (Bucci et al., 2000). To gain further insight into the role of Rab7 on TrkA signaling, we also transfected WT-Rab7/GFP or CA-Rab7/GFP into PC12 cells, followed by a brief NGF stimulation, surface strip, and reincubation for different time points, as described above for GFP and DN-Rab7/ GFP. As shown in Figure 5A, levels of pTrkA in cells expressing CA-Rab7/GFP or WT-Rab7/GFP were very low and resembled those in GFP-transfected control cells.

Total TrkA levels remained comparably stable in DN-Rab7/ GFP-transfected cells within the time frame of our experiments (Fig. 5A, lower panels). The latter observation was somewhat surprising, because we expected total TrkA levels to increase in NGF-stimulated cells transfected with DN-Rab7/GFP. In line with this expectation, one of our previous experiments showed increased total TrkA levels in lysates of cells treated with CHX at $6 \mathrm{~h}$ after a brief NGF stimulation (compare Fig. 3). A potential resolution is provided by a previous report. TrkA activation in PC12 cells rapidly downregulates the de novo synthesis of TrkA mRNA and protein (Zhou et al., 1995). Potentially, the rather stable total TrkA levels over time (Fig. 5A) can be explained by the fact that there are two populations of cells on tissue culture plates transfected with the DN-Rab7/GFP construct, corresponding to one large population of untransfected cells and a second small population of DN-Rab7/GFP-transfected cells. Potentially, our brief NGF stimulation differentially affected the total levels of TrkA in these two PC12 cell populations by decreasing de novo TrkA synthesis and increasing accumulating TrkA in cells expressing DN-Rab7/GFP (because of an endosomal traffic block upstream of lysosomes), whereas at the same time, TrkA levels in neighboring nontransfected cells remained stable, as in GFPtransfected sister plates used as a negative control. Thus, a TrkA increase in DN-Rab7/GFP-expressing cells could be masked in pooled total lysates.

Subsequently, we assessed whether endosomal accumulation of phosphorylated TrkA also affected the activation state of the major TrkA downstream signaling mediators, Erk1/2 and Akt (Segal and Greenberg, 1996). As shown in Figure 6A, we found that a short NGF stimulation followed by surface strip and reincubation in NGF-free medium for different time points resulted in the appearance of pErk1/2 bands in DN-Rab7/GFPtransfected cells and GFP-transfected control cells (Fig. 6A). Compared with GFP-expressing control cells, the pErk1/2 bands in plates transiently transfected with DN-Rab7/GFP were stronger and more sustained than in control plates transfected with GFP. As for pTrkA, the pronounced effect of DN-Rab7/GFP expression on sustained Erk1/2 activation was still evident after $24 \mathrm{~h}$ of incubation in NGF-free medium. It was interesting that we did not find pTrkA bands in lysates of control GFP cells kept at $2 \mathrm{~h}$ in NGF-free medium after a previous $10 \mathrm{~min}$ NGF stimulation, whereas pErk1/2 bands (and pAkt bands, see below) were readily detectable in the same lysates. A potential explanation might be that the kinetics of TrkA dephosphorylation by specific phosphatases such as SHP-1 (Src homology domain 2-containing tyrosine phosphatase-1) are faster than the kinetics of Erk1/2 dephosphorylation (Marsh et al., 2003).

The presence of persistent pErk1/2 bands in GFP control cells offered an opportunity to examine the effect of the constitutive active Rab7 construct CA-Rab7/GFP on NGF signaling. If Rab7 activity influenced TrkA activity, a CA mutation might show the mirror image effect compared with the $\mathrm{DN}$ variant. As shown in Figure $6 A$, this was indeed the case in this assay. As expected, the expression of CA-Rab7/GFP diminished Erk1/2 phosphorylation in response to a brief stimulation with NGF, whereas expression 


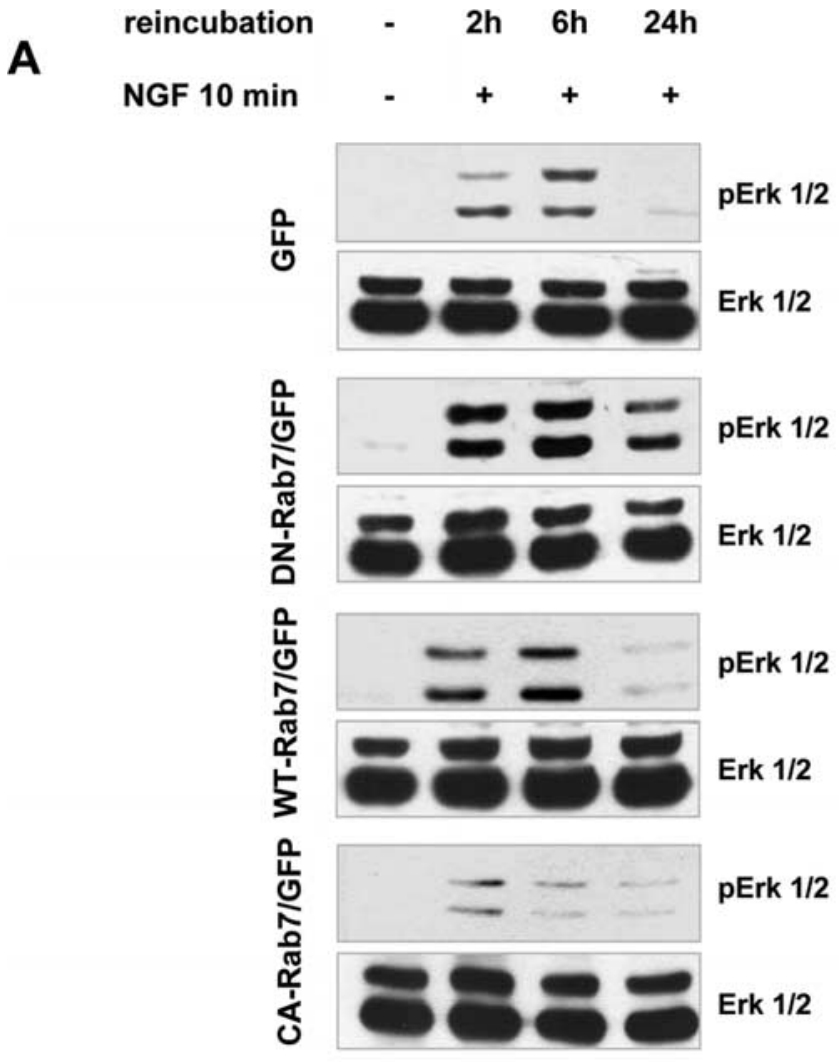

B

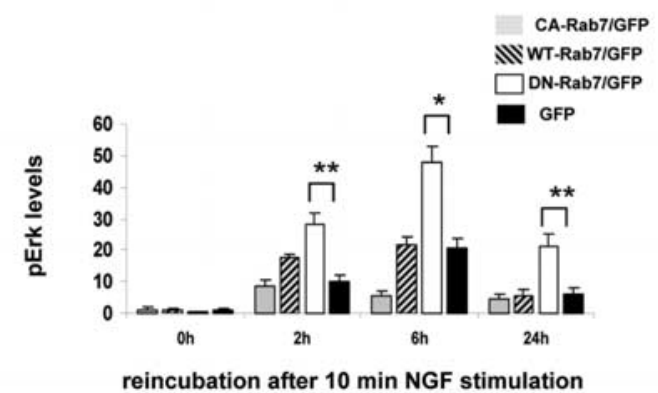

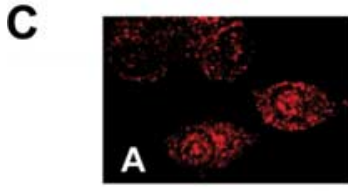

pErk1/2

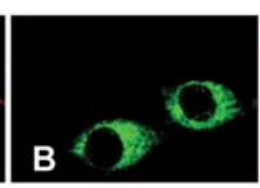

DN-Rab7/GFP

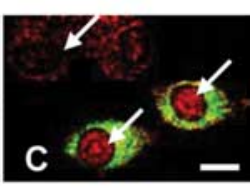

overlay
Figure 6. Enhanced pErk1/2 levels in PC12 cells expressing DN-Rab7/GFP. A, The same lysates as those in Figure 5 were probed for tyrosine-phosphorylated Erk1/2 (pErk1/2). We found persistent enhanced activation of Erk $1 / 2$ in DN-Rab7/GFP-expressing cells compared with GFPexpressing control cells. Decreased pErk1/2 levels are shown in cells transfected with CA-Rab7/ GFP. Subsequently, membranes were stripped and reprobed with antibodies against unphosphorylated Erk $1 / 2$ as a loading control (bottom). Representative blots are shown. $\boldsymbol{B}$, Films derived from four separate experiments were quantified by densitometry. Values of $p$ Erk are compared with control values (unstimulated). Error bars represent SD. ${ }^{*} p<0.05 ;{ }^{* *} p<0.01$. C, Confocal immunofluorescence analysis of pErk $1 / 2$ in DN-Rab7/GFP cells stimulated with NGF. Increased nuclear localization of pErk1/2 (red, arrow) in cells expressing DN-Rab7/GFP (green) are compared with untransfected control cells. Scale bar, $10 \mu \mathrm{m}$.

of WT-Rab7/GFP had no major effect at 6 and 24 h. Densitometric analysis of four separate experiments (Fig. 6B) revealed that pErk1/2 levels in DN-Rab7/GFP-expressing cells were increased by 2.8 -fold at $2 \mathrm{~h}(p<0,001)$, by 2.3 -fold at $6 \mathrm{~h}(p<0,01)$, and by 3.3-fold at $24 \mathrm{~h}(p<0,01)$ compared with pErk1/2 levels in GFP-expressing control cells at these time points. In contrast, pErk1/2 levels in CA-Rab7/GFP-expressing cells were 0.82 -fold at $2 \mathrm{~h}, 0.26$-fold at $6 \mathrm{~h}$, and 0.73 -fold at $24 \mathrm{~h}$ compared with pErk $1 / 2$ levels in GFP-expressing control cells at these time points $(p<$ $0.01)$.

Given the availability of excellent anti-pErk1/2 antibodies suitable for immunofluorescence experiments, NGF-induced nuclear translocation of pErk1/2 was investigated using confocal microscopy. As described above, DN-Rab7/GFP-transfected PC12 cells were stimulated for 10 min with NGF. After surface strip and reincubation for $2 \mathrm{~h}$ in NGF-free medium, cells were processed for immunostaining (Saxena et al., 2005). As shown in Figure 6C, NGF-stimulated DN-Rab7/GFP-expressing cells showed stronger nuclear pErk1/2 staining (red) than in untransfected neighboring control cells on the same coverslip.

We also examined the phosphorylation of Akt in cells transiently transfected with DN-Rab7/GFP or GFP. Interestingly, in contrast to the Erk1/2 pathway, the PI3K/Akt pathway showed no apparent difference in the activation pattern between DN-Rab7/ GFP- and GFP-expressing cells (Fig. 7A), because robust phosphorylation was observed after up to $6 \mathrm{~h}$ of reincubation in NGFfree medium in both cases. Moreover, Akt phosphorylation was downregulated after $24 \mathrm{~h}$ in both DN-Rab7/GFP- and GFPexpressing control cells. This result supports the notion that the previously observed increased activation of the Erk1/2 pathway is a specific effect of Rab7 inhibition because DN-Rab7/GFP had no effect on this other TrkA signaling pathway. We also transfected PC12 cells with CA-Rab7/GFP and WT-Rab7/GFP constructs, followed by immunoblotting of lysates for pAkt. Whereas expression of WT-Rab7/GFP had no major effect on pAkt levels, the expression of the constitutive active variant CA-Rab7/GFP lead to diminished pAkt levels. Densitometric quantification was performed on four separate experiments. As shown in Figure $7 B$, pAkt levels in CA-Rab7/GFP-expressing cells were threefold lower at $2 \mathrm{~h}(p<0.01)$, fourfold lower at $6 \mathrm{~h}(p<0.001)$, and twofold lower at $24 \mathrm{~h}(p<0.01)$ compared with pAkt levels in GFP-expressing control cells.

\section{Inhibition of Rab7 potentiates NGF induced} neurite outgrowth

In the presence of NGF, PC12 cells cease to proliferate and instead start differentiating, as morphologically evident by neurite outgrowth (Greene and Shooter, 1980). Previous work has shown that Erk1/2 activation preferentially occurs on endosomes (Vieira et al., 1996; Xue and Lucocq, 1998) and that NGFinduced neurite outgrowth in PC12 cells depends on Erk1/2 signaling (Fukuda et al., 1995) that preferentially emerges from endosomal TrkA receptors (Zhang et al., 2000). Thus, we next examined the effect of Rab7 inhibition on neurite outgrowth. PC12 cells were transfected with DN-Rab7/GFP or GFP as control and either stimulated briefly for $10 \mathrm{~min}$ with NGF to load cells with signaling endosomes containing activated TrkA receptors or left nonstimulated. Previous work with PC12 cells showed that such brief NGF stimulation protocols exert significant effects on the expression of differentiation-related genes but that they are not sufficient for triggering morphological differentiation and neurite outgrowth (Toledo-Aral et al., 1995). After brief NGF stimulation, cells were stripped of surface-bound NGF as described above (compare Figs. 5-7) and subsequently incubated for $24 \mathrm{~h}$ in NGF- and serum-free medium (DMEM and 0.1\% BSA) before neurite outgrowth was assessed. As shown in Figure 8, the expression of DN-Rab7/GFP was not sufficient to induce 


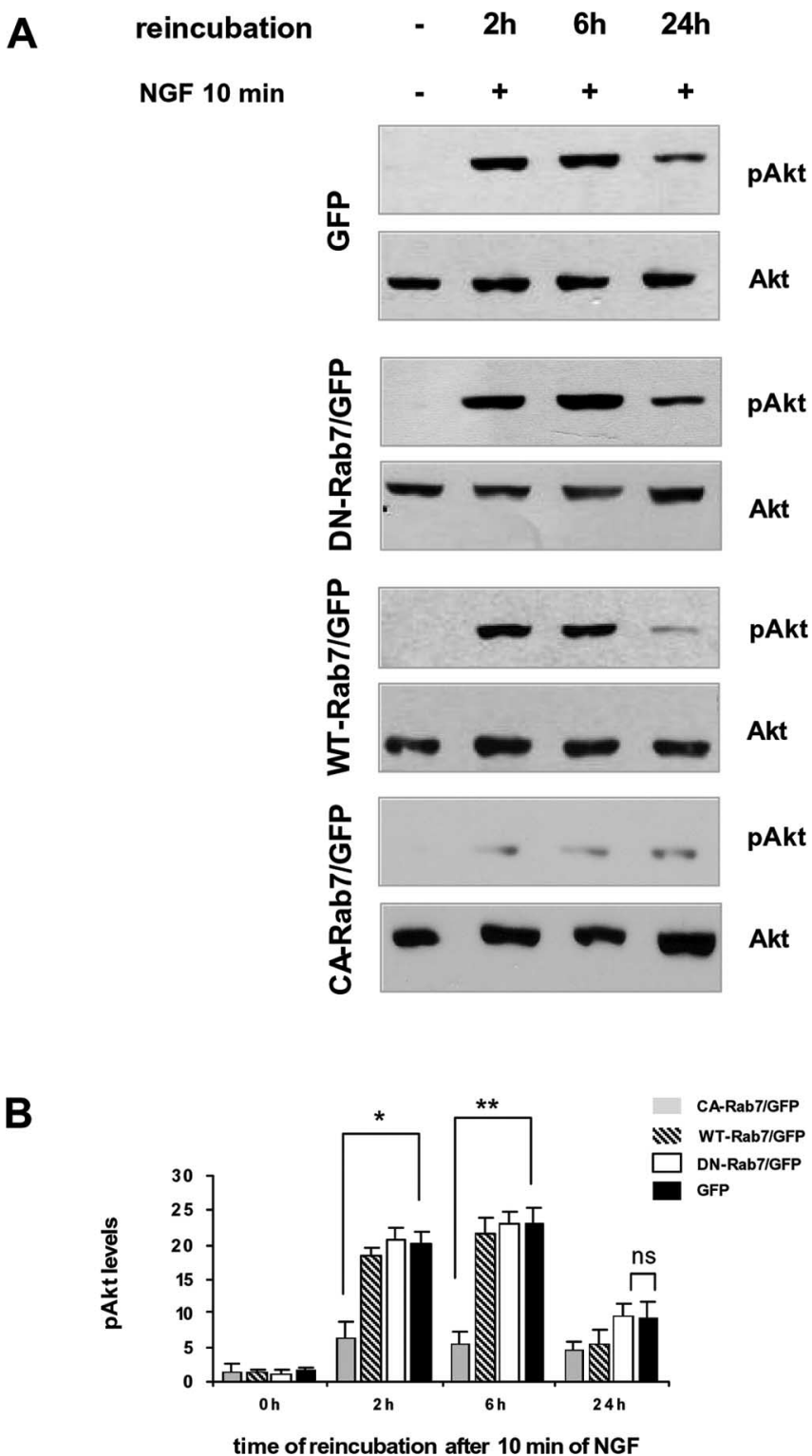

Figure 7. Unaltered Akt phosphorylation in PC12 cells expressing DN-Rab7/GFP. A, The same lysates as those in Figures 5 and 6 were probed for phosphorylated Akt (pAkt). Subsequently, membranes were stripped and reprobed with antibodies against unphosphorylated Akt as a loading control (bottom). Representative blots are shown. $\boldsymbol{B}$, Films derived from four separate experiments were quantified by densitometry. Values of pAkt are compared with control values (unstimulated). Error bars represent SD. ns, Not significant. ${ }^{*} p<0.05$; ${ }^{* *} p<0.01$.

outgrowth of long neurites in unstimulated PC12 cells. On the other hand, a brief 10 min stimulation with NGF in DN-Rab7/ GFP-expressing cells was sufficient to promote impressive neurite outgrowth after $24 \mathrm{~h}$ in NGF-free medium. In contrast, the same brief NGF treatment did not trigger differentiation in GFPexpressing control cells nor in CA-Rab7/GFP-expressing cells (Fig. 8).

We quantified the NGF-induced neurite outgrowth in GFPexpressing control cells and WT-Rab7/GFP-, CA-Rab7/GFP-, and DN-Rab7/GFP-expressing cells (Fig. $8 B$ ). Without NGF stimulation, both DN-Rab7/GFP- and GFP-expressing cells grew very few neurites. This was strikingly altered in DN-Rab7/GFPexpressing cells: a 10 min stimulation with NGF, followed by surface strip and reincubation for $24 \mathrm{~h}$ in NGF-free medium
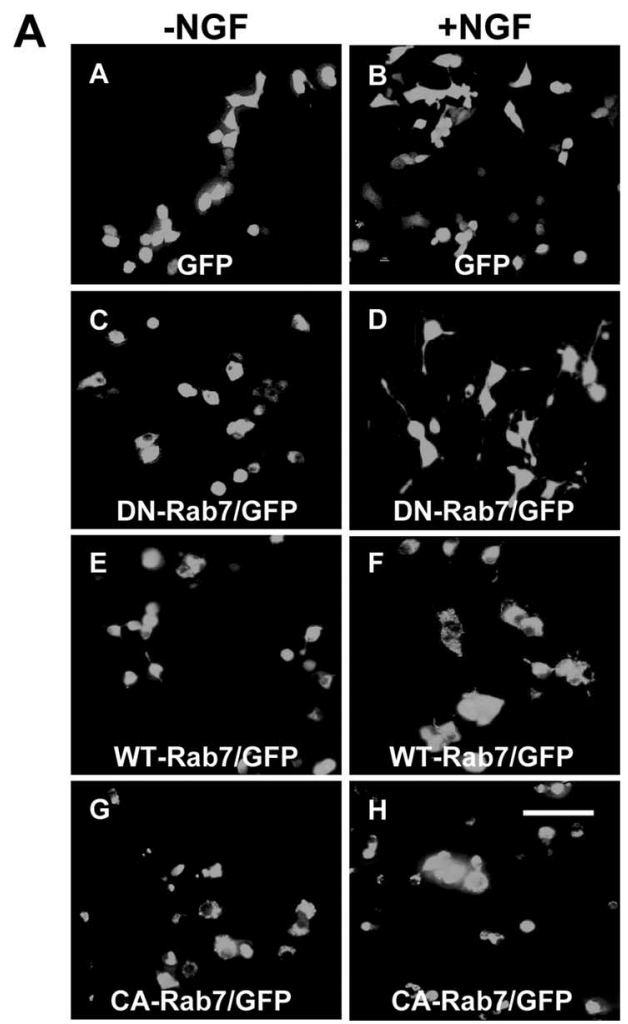

B
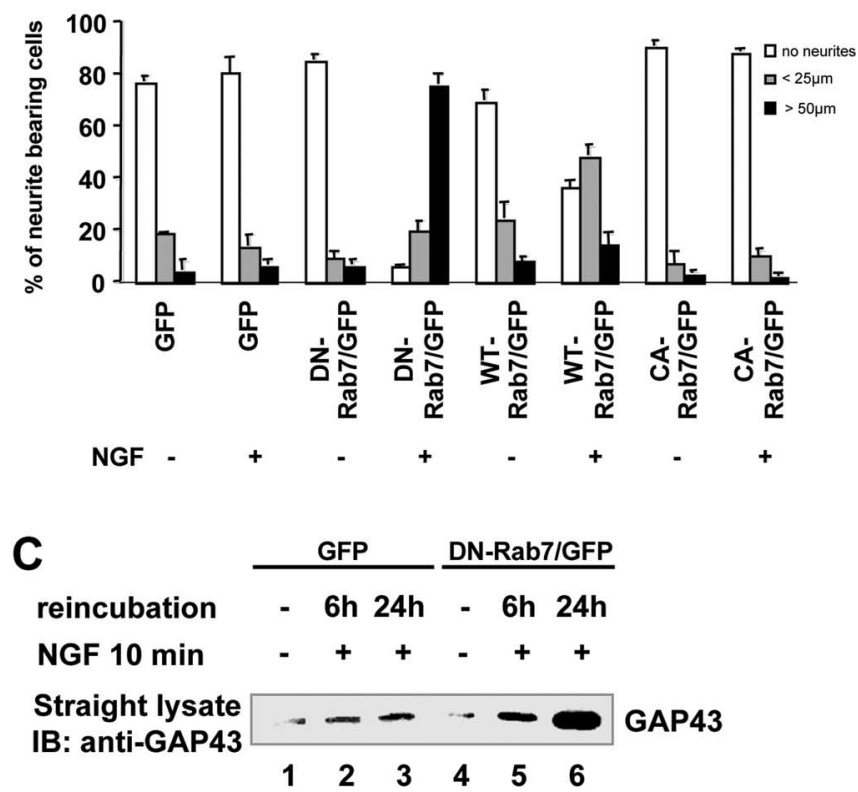

Figure 8. Rab7 inhibition results in potentiated neurite outgrowth in response to brief stimulation with NGF. $A$, Epifluorescence images of PC12 cells expressing GFP (control; $\boldsymbol{A}, \boldsymbol{B})$ or DN-Rab7/GFP $(\boldsymbol{C}, \boldsymbol{D})$, WT-Rab7/GFP $(\boldsymbol{E}, \boldsymbol{F})$, or CA-Rab7/GFP $(\boldsymbol{G}, \boldsymbol{H})$ stimulated for 10 min with (+NGF) or without (-NGF) NGF, followed by surface strip and reincubation in NGF-free medium for $24 \mathrm{~h}$. DN-Rab7/GFP cells differentiated in response to a $10 \mathrm{~min}$ NGF stimulus, whereas control cells failed to do so. Scale bar, $100 \mu \mathrm{m}$. $\boldsymbol{B}$, Graphical representation of $\boldsymbol{A}$ from three independent experiments. The number of cells without neurites (no neurites) or with neurites $<25 \mu \mathrm{m}$ or $>50 \mu \mathrm{m}$ were determined. $p<0.00001$, DN-Rab7/GFP-transfected cells and GFP-transfected control cells. C, Western blotting with an antibody directed against a neuronal differentiation marker. PC12 cells transfected with GFP (control) or DN-Rab7/GFP were stimulated for 10 min with NGF, followed by ligand strip and reincubation in NGF-free medium for the indicated time points. Subsequently, cells were lysed, and equal amounts of protein were subjected to immunoblotting with antibodies directed against GAP-43. A representative blot is shown. IB, immunoblot. 
(DMEM and $0.1 \%$ BSA), resulted in $84.6 \pm 2.6 \%$ of cells possessing neuronal processes of $\geq 50 \mu \mathrm{m}$ length. It was interesting that we previously observed pErk $1 / 2$ bands in lysates of NGFstimulated, GFP-transfected control cells (compare Fig. 6) but did not observe neurite outgrowth in these cells (Fig. 8). Potentially, the pERK1/2 levels in these cells were below the threshold necessary for the induction of long neurites. Indeed, pERK1/2 levels were low at $24 \mathrm{~h}$ after brief NGF stimulation, which is the time point at which neurite outgrowth was quantified. Alternatively, signaling pathways not examined by us might also contribute to neurite outgrowth in PC12 cells. This hypothesis is supported by our finding that PC12 cells expressing WT-Rab7/GFP showed a somewhat increased responsiveness to limited NGF stimulation in neurite outgrowth assays at $24 \mathrm{~h}$ after brief stimulation with NGF (Fig. 8), without enhanced pErk1/2 levels at $24 \mathrm{~h}$ after brief stimulation with NGF (compare Fig. 6). Previous studies revealed that overexpression of WT-Rab7 might sometimes exert either a slight CA (Bucci et al., 2000) or a slight DN effect (Dupre et al., 2003). Thus, the finding of WT-Rab7/GFP overexpression leading to slightly enhanced neurite outgrowth could nevertheless be explained by a slight DN effect on Rab7 function, leading to enhancement of TrkA signaling pathways not examined by us.

NGF-induced differentiation of PC12 cells in vitro as well as neuronal regeneration in vivo is associated with upregulation of growth-associated protein 43 (GAP-43) (Skene et al., 1986; Irwin et al., 2002). Therefore, we assessed whether Rab7 activity affected the expression levels of GAP-43 protein in PC12 cells. PC12 cells were transfected with DN-Rab7/GFP or GFP as control and were either stimulated briefly for $10 \mathrm{~min}$ with NGF or not stimulated. Cells were then stripped of surface-bound NGF as described above and subsequently incubated for 6 or $24 \mathrm{~h}$ in serum-free medium. Cells were lysed, and equal amounts of protein lysates were subjected to immunoblotting with an antibody against GAP-43. As shown in Figure $8 C$, we found a robust increase in GAP-43 levels after 6 or $24 \mathrm{~h}$ of reincubation in serumfree medium in DN-Rab7/GFP-transfected cells but not in GFPtransfected control cells (Fig. 8C, compare lanes 2 and 3, 5 and 6). These data indicate that Rab7 activity exerts a decisive influence on the two most prototypical NGF effects, neurite outgrowth and neuronal differentiation.

\section{Discussion}

RTK internalization and endosomal trafficking is important for RTK signal transduction (Di Fiore and De Camilli, 2001). Therefore, the regulation of RTK trafficking is important for controlling RTK signaling. But how is the endosomal sorting of RTKs regulated? Work in non-neuronal cells has established an important role for Rab7 in the trafficking of early endosomes and late endosomes. It has recently emerged that in primary neurons and in PC12 cells, activated TrkA is transported in both early and late endosomes (Delcroix et al., 2003; Saxena et al., 2005). Therefore, Rab7 might also play an important role in controlling the trafficking of RTKs in neuronal cells. In this study, we addressed this hypothesis by examining the trafficking of the RTK TrkA in a neuronal cell line in which Rab7 function could be manipulated by expression of a DN construct. We found that Rab7 controls the post-endosomal trafficking of TrkA-bearing endosomes. This is the first report demonstrating a role of Rab7 in trafficking of RTKs in general and of TrkA in particular. Together with recent reports on a similar role of the related Rab5 in the initial endocytic trafficking of other RTKs (Barbieri et al., 2004; Dinneen and Ceresa, 2004; Lanzetti et al., 2004), our findings support the no- tion that the trafficking of signaling receptors is under control of the large family of Rab GTPases.

RTKs continue to signal after their internalization into endosomes. Certain specialized endosomal organelles might represent signaling platforms from which specific pathways emerge (Howe et al., 2001; Sorkin and Von Zastrow, 2002). Because Rab7 controls the endosomal trafficking of TrkA, we wanted to test whether Rab7 would also control TrkA signaling. We found that Rab7 inhibition in NGF-stimulated PC12 cells not only resulted in enhanced accumulation of TrkA within endosomes but also increased phosphorylation of TrkA and downstream effects such as phosphorylation of Erk1/2, neurite outgrowth, and GAP-43 expression. Our report is the first to demonstrate a role of Rab7 in signaling of RTKs and indicates a novel mechanistic link between RTK trafficking and signaling.

Previous work using overexpression of a DN form of the large GTPase dynamin in PC12 cells established that inhibition of the GTPase activity of dynamin inhibited NGF-induced neurite outgrowth by inhibition of TrkA internalization (Zhang et al., 2000). In contrast, we now report that inhibition of an unrelated GTPase, Rab7, inhibited endosomal trafficking of TrkA and potentiated Erk1/2 activation as well as neurite outgrowth. Because dynamin controls trafficking events located "upstream" of Rab7 (the pinching of clathrin-coated vesicles from the plasma membrane), this suggests that activation of Erk1/2 and neuritogenic signaling emerges from an endosomal compartment localized between a compartment under control of dynamin on the one side and Rab7 on the other side, compatible with clathrin-coated pits, early endosomes, and late endosomes. Evidence from the literature points toward early endosomes and late endosomes as potential candidates, because the MAPK scaffold p14 resides on the cytoplasmic face of late endosomes (Wunderlich et al., 2001) and activated Erk1/2 were recovered in density gradient fractions containing early endosomes (Delcroix et al., 2003). In future studies, it will be important to determine the specific endosomal nucleation point of neuritogenic TrkA signaling.

In contrast to Erk1/2, no effect on NGF-induced phosphorylation of Akt-transfected cells was seen in DN-Rab7/GFPexpressing cells. This finding suggests that in PC12 cells, Akt signaling does not emerge from endosomes that are under control of Rab7. This hypothesis is in line with a study concluding that NGF-induced Akt activation in PC12 cells preferentially takes place at the cell surface instead of endosomes (Zhang et al., 2000). However, we also found that a CA-Rab7 construct diminished pAkt levels after NGF stimulation. Previous studies reported various subcellular localizations of activated Akt (e.g., at the cell surface, in the nucleus, at the Golgi apparatus, and on mitochondria) (Filippa et al., 2000; Sasaki et al., 2003). Thus, additional studies will be necessary to examine in more detail the neuronal organelles from which Akt signaling emerges, as well as the role that Rab7 might play in this process.

Is there a link between neurodegenerative diseases, neurotrophin receptor transport, and dysfunction of Rab GTPases? Recently, neurodegenerative disorders have been linked to defective organelle trafficking (Kruttgen et al., 2003). One report showed that the molecular motor dynein is required for endosomal transport of internalized, activated TrkB from axon terminals to cell bodies; when this dynein-based transport is inhibited, neurotrophin stimulation of axon terminals does not support survival (Heerssen et al., 2004). Recent studies found that Rab7 is mutated in patients suffering from CMT2B or HSN1 (Verhoeven et al., 2003; Houlden et al., 2004). Because Rab7 interacts indirectly with dynein (Cantalupo et al., 2001; Jordens et al., 2001), our 
finding of a TrkA-Rab7 complex (Fig. 4) indicates a novel link between Rabs, neurotrophin receptor transport, and neurodegeneration. It is not known whether the observed Rab7 mutations in patients actually increases or decreases the activity of Rab7. Neuronal death could be explained in either case: if there was a slight increase in Rab7 activity in these patients, neurotrophic effects depending on Erk1/2 signaling might be decreased, leading to neurodegeneration. In case of a slight decrease in Rab7 function, one could imagine that, although Trk and Erk1/2 signaling will be enhanced, the trafficking of nutritional ligands (such as LDL) (compare Fig. 2 B) might be altered. On a longer time scale, this should lead to metabolic dysfunction despite increased neurotrophin signaling. It might be of importance that even elevation of WT-Rab7 levels by overexpression slightly affects TrkA-induced neurite outgrowth, in line with previous reports that overexpression of WT-Rabs leads to slight alterations in readouts for Rab activity. Thus, subtle alterations in Rab7 halflife caused by Rab7 point mutations found in polyneuropathies could lead to increased or decreased Rab7 protein levels that in turn might affect downstream processes relevant for neuronal survival or neurite integrity.

How is the activity of Rab7 regulated and how does Rab7 regulate the trafficking of signaling endosomes? In general, Rab GTPases are regulated by guanine nucleotide exchange factors and GTPase-activating factors (Stenmark and Olkkonen, 2001). Some Rab7 interacting proteins have been isolated that might be involved in upstream or downstream signal transduction. The function of one of these, RILP, is the best understood. The Rab7 effector RILP binds to the C terminus of Rab7, which prevents additional GTP cycling of Rab7, thereby sustaining Rab7 activity (Jordens et al., 2001). RILP expression in transfected cells induces the recruitment of functional dynein-dynactin motor complexes to Rab7 containing late endosomes, leading to minus-end transport. In future experiments, it will be interesting to test whether RILP activity plays a role in TrkA traffic control and whether Rab7 activity is actually under control of NGF or other external signals such as depolarization.

In summary, we show that Rab7 controls both TrkA trafficking and signaling (for a schematic, see supplemental Fig. 3, available at www.jneurosci.org as supplemental material). Given the well established role of Rab7 in the traffic control of early and late endosomes along microtubules, it is likely that Rab7 controls TrkA signaling by controlling endosomal TrkA traffic. Thus, we hypothesize that Rab7 controls the "signaling endosomal residence time" of RTKs and therefore regulates their "endosomal signaling time," keeping TrkA in an endosomal subpopulation favorable for Erk1/2 activation and promotion of neurite outgrowth. By increasing or decreasing Rab7 activity, cells might control the late endosomal residence time of an RTK and thereby signal duration as well as subcellular localization of the signaling platforms. In addition, our study suggests that in humans, neurodegeneration or axonal pathologies could be caused by dysregulation of Rab7 and neurotrophin receptor traffic control. Future studies are being performed to address this hypothesis.

\section{References}

Bananis E, Nath S, Gordon K, Satir P, Stockert RJ, Murray JW, Wolkoff AW (2004) Microtubule-dependent movement of late endocytic vesicles in vitro: requirements for dynein and kinesin. Mol Biol Cell 15:3688-3697.

Barbieri MA, Fernandez-Pol S, Hunker C, Horazdovsky BH, Stahl PD (2004) Role of rab5 in EGF receptor-mediated signal transduction. Eur J Cell Biol 83:305-314

Bernd P, Greene LA (1984) Association of 125I-nerve growth factor with PC12 pheochromocytoma cells. Evidence for internalization via high- affinity receptors only and for long-term regulation by nerve growth factor of both high- and low-affinity receptors. J Biol Chem 259:15509-15516.

Bronfman FC, Tcherpakov M, Jovin TM, Fainzilber M (2003) Ligandinduced internalization of the $\mathrm{p} 75$ neurotrophin receptor: a slow route to the signaling endosome. J Neurosci 23:3209-3220.

Bucci C, Thomsen P, Nicoziani P, McCarthy J, van Deurs B (2000) Rab7: a key to lysosome biogenesis. Mol Biol Cell 11:467-480.

Cantalupo G, Alifano P, Roberti V, Bruni CB, Bucci C (2001) Rabinteracting lysosomal protein (RILP): the Rab7 effector required for transport to lysosomes. EMBO J 20:683-693.

Delcroix JD, Valletta JS, Wu C, Hunt SJ, Kowal AS, Mobley WC (2003) NGF signaling in sensory neurons: evidence that early endosomes carry NGF retrograde signals. Neuron 39:69-84.

Di Fiore PP, De Camilli P (2001) Endocytosis and signaling. An inseparable partnership. Cell 106:1-4.

Dinneen JL, Ceresa BP (2004) Continual expression of Rab5(Q79L) causes a ligand-independent EGFR internalization and diminishes EGFR activity. Traffic 5:606-615.

Dupre DJ, Chen Z, Le Gouill C, Theriault C, Parent JL, Rola-Pleszczynski M, Stankova J (2003) Trafficking, ubiquitination, and down-regulation of the human platelet-activating factor receptor. J Biol Chem 278:48228-48235.

Ehlers MD, Kaplan DR, Price DL, Koliatsos VE (1995) NGF-stimulated retrograde transport of trkA in the mammalian nervous system. J Cell Biol 130:149-156.

Feng Y, Press B, Wandinger-Ness A (1995) Rab 7: an important regulator of late endocytic membrane traffic. J Cell Biol 131:1435-1452.

Filippa N, Sable CL, Hemmings BA, Van Obberghen E (2000) Effect of phosphoinositide-dependent kinase 1 on protein kinase $\mathrm{B}$ translocation and its subsequent activation. Mol Cell Biol 20:5712-5721.

Fukuda M, Gotoh Y, Tachibana T, Dell K, Hattori S, Yoneda Y, Nishida E (1995) Induction of neurite outgrowth by MAP kinase in PC12 cells. Oncogene 11:239-244.

Ginty DD, Segal RA (2002) Retrograde neurotrophin signaling: Trk-ing along the axon. Curr Opin Neurobiol 12:268-274.

Greene LA, Shooter EM (1980) The nerve growth factor: biochemistry, synthesis, and mechanism of action. Annu Rev Neurosci 3:353-402.

Grimes ML, Zhou J, Beattie EC, Yuen EC, Hall DE, Valletta JS, Topp KS, LaVail JH, Bunnett NW, Mobley WC (1996) Endocytosis of activated TrkA: evidence that nerve growth factor induces formation of signaling endosomes. J Neurosci 16:7950-7964.

Heerssen HM, Pazyra MF, Segal RA (2004) Dynein motors transport activated Trks to promote survival of target-dependent neurons. Nat Neurosci 7:596-604.

Hosang M, Shooter EM (1987) The internalization of nerve growth factor by high-affinity receptors on pheochromocytoma PC12 cells. EMBO J 6:1197-1202.

Houlden H, King RH, Muddle JR, Warner TT, Reilly MM, Orrell RW, Ginsberg L (2004) A novel RAB7 mutation associated with ulcero-mutilating neuropathy. Ann Neurol 56:586-590.

Howe CL, Mobley WC (2004) Signaling endosome hypothesis: a cellular mechanism for long distance communication. J Neurobiol 58:207-216.

Howe CL, Valletta JS, Rusnak AS, Mobley WC (2001) NGF signaling from clathrin-coated vesicles: evidence that signaling endosomes serve as a platform for the Ras-MAPK pathway. Neuron 32:801-814.

Irwin N, Chao S, Goritchenko L, Horiuchi A, Greengard P, Nairn AC, Benowitz LI (2002) Nerve growth factor controls GAP-43 mRNA stability via the phosphoprotein ARPP-19. Proc Natl Acad Sci USA 99:12427-12431.

Jordens I, Fernandez-Borja M, Marsman M, Dusseljee S, Janssen L, Calafat J, Janssen H, Wubbolts R, Neefjes J (2001) The Rab7 effector protein RILP controls lysosomal transport by inducing the recruitment of dyneindynactin motors. Curr Biol 11:1680-1685.

Jullien J, Guili V, Reichardt LF, Rudkin BB (2002) Molecular kinetics of nerve growth factor receptor trafficking and activation. J Biol Chem 277:38700-38708.

Kaplan DR, Hempstead BL, Martin-Zanca D, Chao MV, Parada LF (1991) The trk proto-oncogene product: a signal transducing receptor for nerve growth factor. Science 252:554-558.

Klein R, Jing SQ, Nanduri V, O'Rourke E, Barbacid M (1991) The trk protooncogene encodes a receptor for nerve growth factor. Cell 65:189-197. 
Kruttgen A, Saxena S, Evangelopoulos ME, Weis J (2003) Neurotrophins and neurodegenerative diseases: receptors stuck in traffic? J Neuropathol Exp Neurol 62:340-350.

Lanzetti L, Palamidessi A, Areces L, Scita G, Di Fiore PP (2004) Rab5 is a signalling GTPase involved in actin remodelling by receptor tyrosine kinases. Nature 429:309-314.

Longva KE, Blystad FD, Stang E, Larsen AM, Johannessen LE, Madshus IH (2002) Ubiquitination and proteasomal activity is required for transport of the EGF receptor to inner membranes of multivesicular bodies. J Cell Biol 156:843-854.

Marsh HN, Dubreuil CI, Quevedo C, Lee A, Majdan M, Walsh GS, Hausdorff S, Said FA, Zoueva O, Kozlowski M, Siminovitch K, Neel BG, Miller FD, Kaplan DR (2003) SHP-1 negatively regulates neuronal survival by functioning as a TrkA phosphatase. J Cell Biol 163:999-1010.

Miaczynska M, Christoforidis S, Giner A, Shevchenko A, Uttenweiler-Joseph S, Habermann B, Wilm M, Parton RG, Zerial M (2004) APPL proteins link Rab5 to nuclear signal transduction via an endosomal compartment. Cell 116:445-456.

Mukhopadhyay A, Barbieri AM, Funato K, Roberts R, Stahl PD (1997) Sequential actions of Rab5 and Rab7 regulate endocytosis in the Xenopus oocyte. J Cell Biol 136:1227-1237.

Neet KE, Campenot RB (2001) Receptor binding, internalization, and retrograde transport of neurotrophic factors. Cell Mol Life Sci 58:1021-1035.

Parton RG, Simons K, Dotti CG (1992) Axonal and dendritic endocytic pathways in cultured neurons. J Cell Biol 119:123-137.

Rupper A, Grove B, Cardelli J (2001) Rab7 regulates phagosome maturation in Dictyostelium. J Cell Sci 114:2449-2460.

Samuels IS, Seibenhener ML, Neidigh KB, Wooten MW (2001) Nerve growth factor stimulates the interaction of ZIP/p62 with atypical protein kinase $\mathrm{C}$ and targets endosomal localization: evidence for regulation of nerve growth factor-induced differentiation. J Cell Biochem 82:452-466.

Sasaki K, Sato M, Umezawa Y (2003) Fluorescent indicators for Akt/protein kinase B and dynamics of Akt activity visualized in living cells. J Biol Chem 278:30945-30951.

Saxena S, Howe CL, Cosgaya JM, Hu M, Weis J, Kruttgen A (2004) Differences in the surface binding and endocytosis of neurotrophins by p75NTR. Mol Cell Neurosci 26:292-307.

Saxena S, Howe CL, Cosgaya JM, Steiner P, Hirling H, Chan JR, Weis J, Kruttgen A (2005) Differential endocytic sorting of p75NTR and TrkA in response to NGF: a role for late endosomes in TrkA trafficking. Mol Cell Neurosci 28:571-587.

Segal RA, Greenberg ME (1996) Intracellular signaling pathways activated by neurotrophic factors. Annu Rev Neurosci 19:463-489.

Sieczkarski SB, Whittaker GR (2003) Differential requirements of Rab5 and Rab7 for endocytosis of influenza and other enveloped viruses. Traffic 4:333-343.
Skene JH, Jacobson RD, Snipes GJ, McGuire CB, Norden JJ, Freeman JA (1986) A protein induced during nerve growth (GAP-43) is a major component of growth-cone membranes. Science 233:783-786.

Snider WD (1994) Functions of the neurotrophins during nervous system development: what the knockouts are teaching us. Cell 77:627-638.

Somsel Rodman J, Wandinger-Ness A (2000) Rab GTPases coordinate endocytosis. J Cell Sci 113:183-192.

Sorkin A, Von Zastrow M (2002) Signal transduction and endocytosis: close encounters of many kinds. Nat Rev Mol Cell Biol 3:600-614.

Stenmark H, Olkkonen VM (2001) The Rab GTPase family. Genome Biol 2:REVIEWS3007.

Thier M, Simon R, Kruttgen A, Rose-John S, Heinrich PC, Schroder JM, Weis J (1995) Site-directed mutagenesis of human CNTF: functional analysis of recombinant variants. J Neurosci Res 40:826-835.

Toledo-Aral JJ, Brehm P, Halegoua S, Mandel G (1995) A single pulse of nerve growth factor triggers long-term neuronal excitability through sodium channel gene induction. Neuron 14:607-611.

Verhoeven K, De Jonghe P, Coen K, Verpoorten N, Auer-Grumbach M, Kwon JM, FitzPatrick D, Schmedding E, De Vriendt E, Jacobs A, Van Gerwen V, Wagner K, Hartung HP, Timmerman V (2003) Mutations in the small GTP-ase late endosomal protein RAB7 cause Charcot-MarieTooth type 2B neuropathy. Am J Hum Genet 72:722-727.

Vieira AV, Lamaze C, Schmid SL (1996) Control of EGF receptor signaling by clathrin-mediated endocytosis. Science 274:2086-2089.

Vitelli R, Santillo M, Lattero D, Chiariello M, Bifulco M, Bruni CB, Bucci C (1997) Role of the small GTPase Rab7 in the late endocytic pathway. J Biol Chem 272:4391-4397.

von Bartheld CS (2004) Axonal transport and neuronal transcytosis of trophic factors, tracers, and pathogens. J Neurobiol 58:295-314.

Wu C, Lai CF, Mobley WC (2001) Nerve growth factor activates persistent Rap1 signaling in endosomes. J Neurosci 21:5406-5416.

Wunderlich W, Fialka I, Teis D, Alpi A, Pfeifer A, Parton RG, Lottspeich F, Huber LA (2001) A novel 14-kilodalton protein interacts with the mitogen-activated protein kinase scaffold $\mathrm{mpl}$ on a late endosomal/lysosomal compartment. J Cell Biol 152:765-776.

Xue L, Lucocq J (1998) ERK2 signalling from internalised epidermal growth factor receptor in broken A431 cells. Cell Signal 10:339-348.

Yano H, Lee FS, Kong H, Chuang J, Arevalo J, Perez P, Sung C, Chao MV (2001) Association of Trk neurotrophin receptors with components of the cytoplasmic dynein motor. J Neurosci 21:RC125(1-7).

Zhang Y, Moheban DB, Conway BR, Bhattacharyya A, Segal RA (2000) Cell surface Trk receptors mediate NGF-induced survival while internalized receptors regulate NGF-induced differentiation. J Neurosci 20:5671-5678.

Zhou J, Valletta JS, Grimes ML, Mobley WC (1995) Multiple levels for regulation of TrkA in PC12 cells by nerve growth factor. J Neurochem 65: $1146-1156$. 